www.nature.com/ejhg

\title{
Connexin 26 mutations in cases of sensorineural deafness in eastern Austria
}

Klemens Frei ${ }^{\star * 1,2}$, Károly Szuhai ${ }^{3}$, Trevor Lucas ${ }^{4}$, Klara Weipoltshammer ${ }^{2}$, Christian Schöfer ${ }^{2}$, Reinhard Ramsebner ${ }^{2}$, Wolf-Dieter Baumgartner ${ }^{1}$, Anton K Raap ${ }^{3}$, Reginald Bittner ${ }^{5}$, Franz J Wachtler ${ }^{2}$ and Karin Kirschhofer ${ }^{1,2}$

${ }^{1}$ Department of Otorhinolaryngology, AKH-8J, Währinger Gürtel 18-20, Vienna, Austria, A-1090; ${ }^{2}$ Department of Histology and Embryology, Schwarzspanierstraße 17, Vienna, Austria, A-1090; ${ }^{3}$ Department of Molecular Cell Biology, Leiden University Medical Center, Wassenaarseweg 72, 2333 AL, Leiden, The Netherlands; ${ }^{4}$ Department of Clinical Pharmacology, AKH-6L, Währinger Gürtel 18-20, Vienna, Austria, A-1090; ${ }^{5}$ Department of Anatomy, Währinger Straße 13, Vienna, Austria, A-1090

Mutations in the connexin $26(\mathrm{Cx} 26)$ gene (GJB2) are associated with autosomal nonsyndromic sensorineural hearing loss. This study describes mutations in the Cx26 gene in cases of familial and sporadic hearing loss $(\mathrm{HL})$ by gene sequencing and identifies the allelic frequency of the most common mutation leading to HL (35delG) in the population of eastern Austria. For this purpose we have developed and applied a molecular beacon based real-time mutation detection assay. Mutation frequencies in the Cx26 gene of individuals from affected families (14 out of 46) and sporadic cases (11 out of 40 ) were $30.4 \%$ and $27.5 \%$, respectively. In addition to known disease related alterations, a novel mutation $262 \mathrm{G} \rightarrow \mathrm{T}$ (A88S) was also identified. 35delG accounted for almost $77 \%$ of all Cx26 mutations detected and displayed an allelic frequency in the normal hearing population of $1.7 \%$ ( 2 out of 120$)$. The high prevalence of the $35 \mathrm{delG}$ mutation in eastern Austria would therefore allow screening of individuals and family members with Cx26 dependent deafness by a highly specific and semi-automated method. European Journal of Human Genetics (2002) 10, 427-432. doi:10.1038/sj.ejhg.5200826

Keywords: Connexin 26; 35delG; mutation; sensorineural deafness; molecular beacons; Austria

\section{Introduction}

Congenital hearing loss affects 1 in 1000 children $^{1,2}$ and about $60 \%$ of all cases are estimated to be of genetic origin. ${ }^{3}$ In approximately $80 \%$ of cases, the hearing impairment is inherited in an autosomal recessive fashion. ${ }^{4}$ More than 100 genes are estimated to be involved in hearing impairment and to date 60 loci $\left(\mathrm{eg}^{5-7}\right)$ have been described in previous studies and 21 related genes have been cloned

${ }^{*}$ Correspondence: Klemens Frei, Department of Otorhinolaryngology, AKH-8], Währinger Gürtel 18-20, Vienna, Austria, A-1090.

Tel: +43 140400 3348; Fax: +43 1404006451 ;

E-mail: klemens.frei@akh-wien.ac.at

Received 11 December 2001; revised 28 March 2002; accepted 25 April 2002 including Connexin $26(\mathrm{Cx} 26)^{8}$, Connexin $31^{9}$ and alpha tectorin. ${ }^{10}$

Connexins are a large family of gap junction forming proteins involved in direct cell-to-cell transfer of small molecules and ions. Cx26 is thought to be important for the recycling of endolymphatic potassium ions. ${ }^{11-13}$

Mutations in the gap junction protein Cx26 play an important role in autosomal nonsyndromic sensorineural HL. Several mutations have been identified which display a variable population distribution ${ }^{14-19}$ and can lead to autosomal dominant ${ }^{20,21}$ and recessive forms of HL. The $35 \mathrm{delG}$ recessive frame shift mutation is the most frequent alteration in European populations with carrier frequencies of 1 out of 35 in southern and 1 out of 79 in northern 
Europe. $^{22} 35 \mathrm{delG}$ is one of the most frequent pathogenic mutations in humans and displays a carrier frequency similar to the deltaF508 mutation of the cystic fibrosis transmembrane conductance regulator gene (CFTR). ${ }^{23}$

In this study, chromosomal sequencing of familial and sporadic cases of nonsyndromic hearing impairment was performed to identify mutations in the Cx26 gene. The 35 delG mutation was the most common alteration found in the Cx26 gene. Five further sporadic mutations were additionally found, one of which has not yet been described. To estimate the $35 \mathrm{delG}$ carrier frequency in the eastern Austrian population, a simple and rapid screening procedure was developed using real time PCR with molecular beacons which represents a highly sensitive, semiautomated method for the detection of 35delG which may be used in routine, clinical diagnosis.

\section{Methods}

Individuals suffering from sensorineural hearing impairment were recruited from the Department of Otorhinolaryngology, University hospital of Vienna and informed consent was obtained from all individuals or the parents of minors. The complete medical histories of all individuals were examined and included otolaryngological status and pure tone audiometrical analysis. Cases of acquired HL and syndromic forms were excluded from the study. In several cases, otoacoustic emissions (OAE), brainstem evoked response audiometry (BERA), ophthalmic evaluations, computer tomography and magnetic resonance imaging of temporal bone and blood analyses were performed to ascertain disease status.

Individuals $(n=57)$ from families $(n=23)$ with at least two affected individuals and sporadic cases $(n=20)$ with no further case of familial deafness were recruited into the study. Inheritance of bilateral deafness was autosomal recessive in 13 familial cases and dominant in seven families and unclear in three cases. HL was classified as moderate in seven families, severe in three and profound in 13 families, congenital in 18 familial cases and postlingual in five families. All 20 sporadic cases ( $3-42$ years; mean 19.8 ) included in this study demonstrated bilateral moderate to profound congenital HL with no signs of progression. The allelic frequency of the $35 \mathrm{delG}$ mutation was determined in 120 unrelated, unaffected Austrian individuals. The DNA samples were randomised and showed a normal sex distribution.

\section{Screening of the Cx26 gene by direct PCR-sequencing}

Genomic DNA was extracted from peripheral blood with a E.Z.N.A. Blood DNA Kit II kit (peqlab, Erlangen, Germany). The Cx26 gene was amplified in a Perkin-Elmer thermal cycler using the primer sets Cx26f, Cx26r as described in Table 1 for 30 cycles with an annealing temperature of $55^{\circ} \mathrm{C}$ for $30 \mathrm{~s}$, extension at $72^{\circ} \mathrm{C}$ for $60 \mathrm{~s}$ and denaturation at $94^{\circ} \mathrm{C}$ for $30 \mathrm{~s}$ as described. ${ }^{18}$ Direct DNA-sequencing on both strands was performed with the PCR primers and the
Table 1 Sequences of amplification primers for molecular beacon PCR-reactions and Connexin 26 whole sequencePCR

\begin{tabular}{ll}
\hline Primers & Sequence \\
\hline Cx26fw & 5'-CCGCCCAGAGTAGAAGATGGAT-3' \\
Cx26rv & 5'-GATCTTTCCAATGCTGGTGGAG-3' \\
Cx26f & 5'-TCTTITCCAGAGCAAACCGCC-3' \\
Cx26r & 5'-TGAGCACGGGTTGCCTCATC-3'
\end{tabular}

Sequences of molecular beacons

\begin{tabular}{ll}
\hline $\begin{array}{l}\text { Molecular } \\
\text { beacon }\end{array}$ & Sequence \\
\hline WT-24-41 & $\begin{array}{l}\text { HEX-5'-GGCTGG TTCACACCCCCAGGATC CCAGCC-3'- } \\
\text { DABCYL }\end{array}$ \\
MT-35delG & $\begin{array}{l}\text { FAM-5'-GGCTGG TTCACACCCCAGGATC CCAGCC-3'- } \\
\text { DABCYL }\end{array}$ \\
\hline
\end{tabular}

Molecular beacon stem regions (underlined) and loop sequences (italics) are shown.

internal forward Cx26fi and reverse Cx26ri primers (see Table 1) on an ABI-377-DNA-Sequencer and aligned to the wild type sequence with GENERUNNER-Software.

\section{Design of molecular beacons}

Molecular beacon probes were designed following the guidelines described by Tyagi and Kramer $^{24}$ available at the related website (www.phri.nyu.edu/molecular_beacons). The intramolecular configuration of molecular beacons and the amplicon probing were modelled using the DNA Mfold program (www.ibc.wustl.edu/-zuker/dna/form1.shtml) that uses thermodynamic parameters established by SantaLucia. ${ }^{25}$ Melting temperatures of probe sequences were calculated using Primer software and molecular beacons were synthesised and purified as described. ${ }^{26}$ The temperature at which there is no contribution of mutant molecular beacon to the fluorescence from wild type target and of wild type molecular beacon to mutant target was determined as described. ${ }^{24}$

\section{Thermal denaturation profiles}

Fluorescence was measured as a function of temperature using an ABI Prism 7700 spectrofluorometric thermal cycler. For mutant (MUT-FAM) and wild type (WT-HEX) molecular beacons, three tubes were prepared. Two of the tubes contained target oligonucleotide sequence complementary to the loop, either wild type (WT-ODN) or mutant (MTODN). The third tube did not contain target oligonucleotide (NO-ODN). The temperature was increased from $15^{\circ} \mathrm{C}$ to $85^{\circ} \mathrm{C}$ with $1^{\circ} \mathrm{C}$ steps and holds for $60 \mathrm{~s}$ each. Laser light of $488 \mathrm{~nm}$ was used for excitation and the fluorescence was monitored during the second $30 \mathrm{~s}$ of each step (see Figure 3). Measurement data were normalised as described. ${ }^{27}$

\section{Molecular beacon-PCR conditions}

Two-colour molecular beacon PCR reactions were carried out in the presence of 6-carboxyfluorescein (FAM)-labelled 
mutant and hexacholo-6-carboxyfluorescein (HEX)-labelled wild type molecular beacons. Amplification reactions were performed in an ABI Prism 7700 spectrofluorometric thermal cycler (Applied Biosystems) with the following cycle conditions: $95^{\circ} \mathrm{C}$ denaturation and enzyme activation step for $10 \mathrm{~min}$ followed by 40 cycles of $95^{\circ} \mathrm{C}$ denaturation for $15 \mathrm{~s}, 62^{\circ} \mathrm{C}$ annealing for $30 \mathrm{~s}$ and $72^{\circ} \mathrm{C}$ elongation for $30 \mathrm{~s}$. Fluorescence spectra were recorded during the annealing phase of each PCR cycle. The Sequence Detection Software (SDS v1.7) of the ABI-Prism 7700 was used to generate the amplification curves. The threshold cycle number $(\mathrm{Ct})$ was calculated with Sequence Detection System (SDS) software v1.7 (Applied Biosystems, The Netherlands) and an automatic setting of the baseline. The baseline value was the average fluorescence value of PCR cycles 3 to 15 plus 10 times its standard deviation (SD). Standard/calibration curves were generated by plotting the Ct values against the log of the input copy numbers.

\section{Results}

Mutation frequency

Analysis of the complete coding region of Cx26 of all individuals $(n=57)$ showed that $29 \%$ of unrelated individuals had mutations in Cx26. In four families and four sporadic cases, the 35delG mutation was homozygous. Hearing impaired individuals with a $35 \mathrm{delG}$ mutation showed a non-progressive HL. In all cases 35delG associated deafness was severe to profound and the degree of HL in both ears was similar. The eight homozygous unrelated individuals represent $18.6 \%$ of the hearing impaired population studied and 35delG accounted for $76.9 \%$ of mutated Cx26 alleles. Five further mutations were detected (see Figure 1). The previously described mutation $\mathrm{L} 90 \mathrm{P}^{28,29}$ was found in one allele in a case of sporadic deafness. The delE119 alteration, which was originally described in combination with a 167delT mutation, ${ }^{28}$ was found in a sporadic case as a compound heterozygote with $35 \mathrm{delG}$. The $71 \mathrm{G} \rightarrow$ A mutation was also found as a homozygote in one family. ${ }^{8}$ $457 \mathrm{~A} \rightarrow \mathrm{G}$, which has been reported as a polymorphic alteration was also found in one family ${ }^{30}$ where the nonsymptomatic father and one of the two hearing impaired daughters were carriers.

\section{Novel mutation}

In addition to previously described mutations, a novel alteration in Cx26 was found. A heterozygous $262 \mathrm{G} \rightarrow \mathrm{T}$ mutation, which would lead to the substitution of an alanine for a serine in the Cx26 protein sequence, was found in a family in which the mother is a non-symptomatic carrier and the male offspring is affected. The second offspring in this family is a non-symptomatic female with wild type genotype (Figures 1 and 2).

Determination of melting and optimal hybridisation temperature to detect the 35delG mutation

Molecular beacon probes fluorensce upon hybrid formation with target sequences. The maximally discriminating hybridisation temperature is dependent on several factors, such as GC content, probe (loop) and stem length. In order to determine the optimal temperature range at which a mole-

\begin{tabular}{|c|c|c|c|c|}
\hline $\begin{array}{l}\text { Mutation } \\
\text { Name } \\
\text { Kind }\end{array}$ & $\begin{array}{l}\text { Position of } \\
\text { nucleic acid }\end{array}$ & $\begin{array}{l}\text { Unrelated familial } \\
\text { cases } \\
\text { Number of cases } \\
\text { and genotype }\end{array}$ & $\begin{array}{l}\text { Sporadic cases } \\
\text { Number of cases } \\
\text { and genotype }\end{array}$ & $\begin{array}{l}\text { Total } \\
\text { (\% of all } \\
\text { mutated } \\
\text { alleles) }\end{array}$ \\
\hline $\begin{array}{l}\text { 35delG } \\
\text { Frameshift }\end{array}$ & $\begin{array}{l}\text { Deletion of one } \\
\mathrm{G} \text { at } 30-35\end{array}$ & $\begin{array}{l}11 / 46 \\
4 \text { Ho: } 35 \mathrm{delG} / 35 \mathrm{delG} \\
3 \text { Het: } 35 \text { delG NT }\end{array}$ & $\begin{array}{l}\text { 9/40 } \\
4 \text { Ho: 35delG/35delG } \\
1 \text { Het: 35delG/ DEL E 119* }\end{array}$ & 76.9 \\
\hline $\begin{array}{l}\text { W24X } \\
\text { Stopcodon }\end{array}$ & $71 \mathrm{G}>\mathrm{A}$ & $\begin{array}{l}2 / 46 \\
1 \mathrm{Ho}: 71 \mathrm{G}>\mathrm{A} / 71 \mathrm{G}>\mathrm{A}\end{array}$ & & 7.7 \\
\hline $\begin{array}{l}\text { A88S } \\
\text { Missense }\end{array}$ & $262 \mathrm{G}>\mathrm{T}$ & $\begin{array}{l}1 / 46 \\
1 \text { Het: } 262 \text { G>T/WT }\end{array}$ & & 3.8 \\
\hline $\begin{array}{l}\text { L90P } \\
\text { Missense }\end{array}$ & $269 \mathrm{~T}>\mathrm{C}$ & & $\begin{array}{l}1 / 40 \\
1 \text { Het: } 269 \text { T>CNT }\end{array}$ & 3.8 \\
\hline $\begin{array}{l}\text { DEL E } 119 \\
\text { Deletion }\end{array}$ & $\begin{array}{l}\text { Deletion of GAG } \\
\text { at } 355-357\end{array}$ & & $\begin{array}{l}1 / 40 \\
1 \text { Het: 35delG/ DEL E } 119^{*}\end{array}$ & 3.8 \\
\hline $\begin{array}{l}\text { V153I } \\
\text { Missense }\end{array}$ & $457 \mathrm{G}>A$ & $\begin{array}{l}1 / 46 \\
1 \text { Het: V153I/WT }\end{array}$ & & 3.8 \\
\hline
\end{tabular}

Figure 1 Mutations identified in the Cx26 gene in cases of non-syndromic hearing loss ( $n=57)$. The nucleotide and amino acid positions of all mutations found in familial and sporadic cases, the genotype and occurrence of these alleles are shown. 
cular beacon probe discriminates between wild type and mutant targets, 'melt-measurements' of the probe/ target combinations were performed. The melt characteristics of duplexes between the molecular beacon and the

\section{TC CAC GC CAKC GC TCCTAGT}

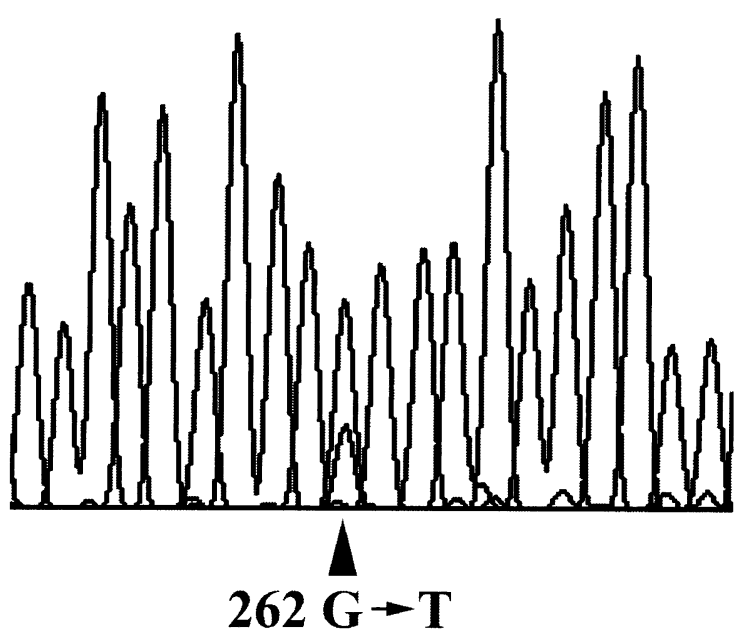

Figure 2 DNA sequence analysis of the Cx26 gene in the 262 $\mathrm{G} \rightarrow \mathrm{T}$ region is shown. The heterozygous sequence was confirmed by sequencing from both sides (reverse sequence not shown). different target oligodeoxynucleotide sequences are shown in Figure 3.

On the basis of the melt measurements, we concluded that at $62^{\circ} \mathrm{C}$ there is a minimal contribution of mutant molecular beacon to the fluorescence from wild type target and of wild type molecular beacon in the case of mutant target (vertical arrow in Figure 3). Therefore, $62^{\circ} \mathrm{C}$ was used as the annealing temperature and primers were designed for optimal priming at this temperature. At the extension temperature of $72^{\circ} \mathrm{C}$, the probe dissociates from the target preventing degradation of molecular beacons by the $5^{\prime}-3^{\prime}$ exonuclease activity of the Taq DNA polymerase. At higher temperatures, the fluorescence intensities equal those of the molecular beacon alone, which adopts a random coil configuration at about $75^{\circ} \mathrm{C}$ as a consequence of the melting of the stem.

\section{Automated 35delG detection}

To enable high throughput, routine diagnostic detection of the Cx26 35delG mutation, a simple and rapid method using molecular beacon based real-time fluorescence PCR was developed. Real-time PCR screening for the Cx26 35delG mutation in the study of individuals and their family members with real-time PCR produced identical results to those obtained by direct sequencing. A representative graphical illustration is shown in Figure 4 where circles represent genotypes; the position of each spot on the $\mathrm{X} ; \mathrm{Y}$ axes varies because of various amounts of DNA loaded. This method was then used to analyse 120 randomised samples for $35 \mathrm{delG}$ in the eastern Austrian population. Analysis demonstrated the presence of two

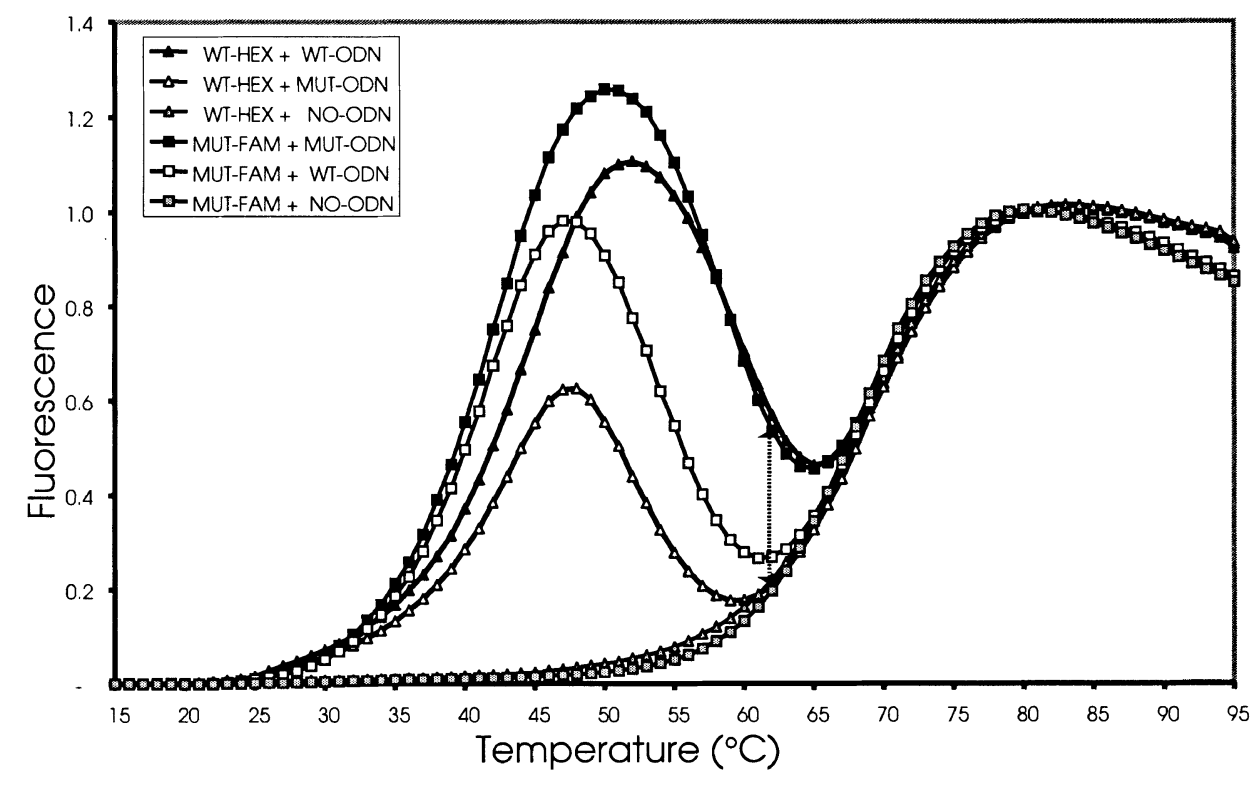

Figure 3 Thermal denaturation profiles of 35delG molecular beacons in the presence of perfectly matching, imperfectly matching and in the absence of complementary oligonucleotide target sequences. FAM labelled mutant and HEX labelled wild type molecular beacons. 


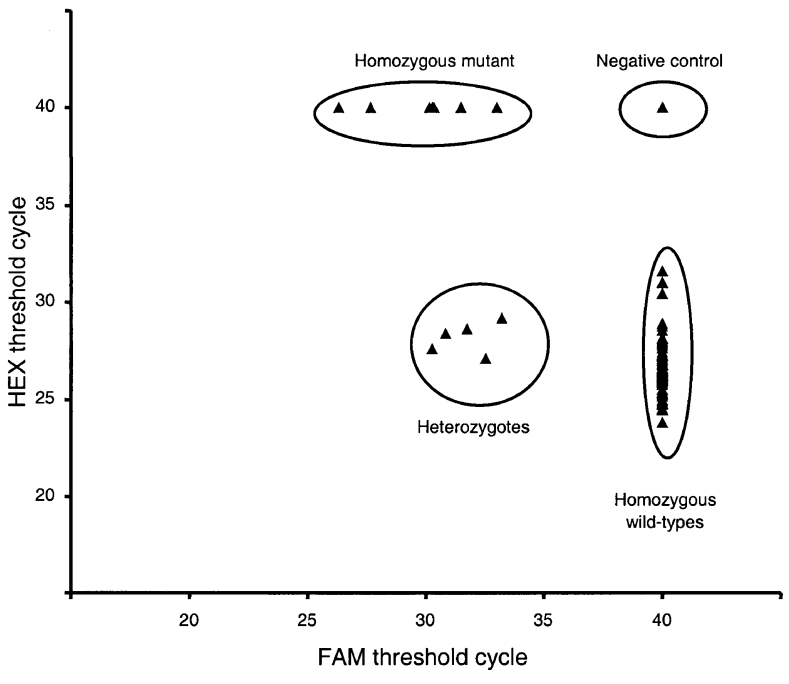

Figure 4 Spectral genotyping by molecular beacon based PCR for the 35 delG mutation. Graphical representation of thresholdcycle values of HEX (wild-type molecular beacon, y) vs FAM (mutant molecular beacon, $x$ ) on a selected set of 96 samples analysed and including a negative control.

heterozygous samples in the sample population representing a relative carrier frequency of $1.7 \%$.

\section{Discussion}

In this study we investigated the prevalence of Cx26 mutations in cases of familial and sporadic sensorineural HL and determined the allelic frequency of the 35delG mutation in the population of eastern Austria. Here we show, that mutations in the Cx26 gene are a main reason for inherited hearing impairment in eastern-Austrian individuals and Cx26 mutations were present in $29.1 \%$ of sufferers.

The 35delG frequency determined was similar to other closely related populations. ${ }^{14,22}$ In this study, the $35 \mathrm{delG}$ mutation was responsible for $76.9 \%$ of changes in the Cx26 gene and the allelic frequency of this mutation in familial (23.9\%) and sporadic cases (22.5\%) was almost equal. Our findings suggest that the high prevalence of the $35 \mathrm{delG}$ mutation in the population of the eastern part of Austria may allow diagnosis and genetic counselling. The prevalence of $35 \mathrm{delG}$ can be compared with one of the most frequent disease mutations known so far, the delta F508 mutation of the CFTR gene, which leads to cystic fibrosis and for which a heterozygotic advantage has been suggested. $^{31}$ These data show the importance of further investigations. Future genetic counselling for the 35delG mutation would require a simplified method for routine detection. The standard technique for the detection of $35 \mathrm{delG}$ is DNA sequencing, which is prone to sequencing errors due to the expansion of the same nucleotide (six guanine residues). In addition, this approach is cost and labour intensive. Several methods such as single-strand conformational polymorphism (SSCP), ${ }^{28}$ allele specific oligonucleotide (ASO) analysis ${ }^{32}$ or sandwich hybridisation $^{33}$ have been described for detecting 35delG. All these methods require further steps following PCR such as hybridisation, electrophoresis or the use of radioactive detection. Real time PCR with molecular beacons has the advantage of an easy and single semi-automated step following DNA isolation and has exceptional discriminatory power for single base mismatches due to the stem-loop structure of the molecule. ${ }^{24}$ Handling is similar to common PCR-methods except for the addition of molecular beacons and a large amount of samples can be analysed simultaneously within a few hours. In addition, real time PCR is a closed tube format assay preventing carry-over contamination and provides a direct readout of results after PCR. In this study, we have shown that molecular beacons can reliably detect the 35delG mutation by comparison to the fully sequenced Cx26 gene. All results obtained from sequencing could be confirmed by this method even with variable amount of initial sample load which makes this newly established assay a highly sensitive, cheap and easy-to-use tool for the detection of $35 \mathrm{delG}$.

In addition to the $35 \mathrm{delG}$ mutation, five different point mutations were detected of which one was novel. A $G \rightarrow T$ transition at nucleotide 262 would result in the substitution of an alanine for a serine at position 88 (A88S), a residue conserved in mouse, rat and sheep Cx26. A dominant mutation at the same position in the connexin 30 gene causes hidrotic ectodermal dysplasia which emphasises the importance of this region. ${ }^{34}$ A88S would lead to an additional hydroxyl group in the second transmembrane domain, which would increase hydrophilicity and reactivity in this region. This novel missense mutation could not be causally connected to deafness and therefore a simple, monogenetic disease model can be excluded. The delE119 mutation is a previously described deletion of a triplet of nucleotides (GAG) at positions 355-357, which leads to the deletion of glutamic acid at amino acid position $119 .^{28}$ In this study, delE119 was found as a compound heterozygote with $35 \mathrm{delG}$. The homozygous $71 \mathrm{~A} \rightarrow \mathrm{G}$ point mutation was found in one family and leads to a premature stop codon as described. ${ }^{8}$ The L90P mutation was detected in only one sporadic case of deafness and was heterozygous. $^{28,29}$ This finding contrasts to the high incidence of L90P $(16.7 \%)$ which has been found in the Tyrolean population. ${ }^{14} \mathrm{~A} \quad \mathrm{G} \rightarrow \mathrm{A}$ transition which would lead to the substitution of a valine residue for isoleucine at position 153 (V153I), which is located in the second extracellular loop and is also highly conserved in mouse, rat and sheep Cx26 has been described as a polymorphic change. ${ }^{30}$

This study emphasises the importance of Cx26 mutations in inherited cases of sensorineural deafness in eastern Austria. Six different mutations were identified of which one was a novel alteration and the 35delG mutation was found to occur in almost $77 \%$ of individuals suffering from 
deafness. We have developed a simple method to detect this most common disease causing Cx26 mutation, which will allow rapid high throughput screening to enable genetic counselling and the determination of allelic frequencies in populations.

\section{Acknowledgements}

This project was supported by Medical Electronics Corporation, Innsbruck, Austria and Hansaton Akustische Geräte G.m.b.H., Salzburg, Austria. We would like to thank Marlene Almeder for technical assistance.

\section{References}

1 Morton NE: Genetic epidemiology of hearing impairment. Ann NY Acad Sci 1991; 630: 16-31.

2 Fortnum H, Davis A: Epidemiology of permanent childhood hearing impairment in Trent Region, 1985-1993. Br J Audiol 1997; 316: $409-416$.

3 Cohen MM, Gorlin RJ: Epidemiology, etiology and genetic patterns; in Gorlin RJ, Toriello HV, Cohen Jr MM (eds): Hereditary hearing loss and its syndromes. Oxford, UK: Oxford University Press; 1995; pp 9-21.

4 Van Camp G, Willems PJ, Smith RJH: Nonsyndromic hearing impairment unparalleled heterogeneity. Am J Hum Genet 1991; 60: $758-765$.

5 Guilford P, Arab SB, Blanchard S et al: A non-syndromic form of neurosensory, recessive deafness maps to the pericentromeric region of chromosome 13q. Nat Genet 1994; 6: 24-28.

6 Coucke P, Van Camp G, Djoyodiharjo B et al: Linkage of autosomal dominant hearing loss to the short arm of chromosome 1 in two families. N Engl J Med 1994; 331: 425-431.

7 Kirschhofer K, Kenyon JB, Hoover DM et al: Autosomal-dominant, prelingual, nonprogressive sensorineural hearing loss: localization of the gene (DFNA8) to chromosome 11q by linkage in an Austrian family. Cytogenet Cell Genet 1998; 82: 126-130.

8 Kelsell DP, Dunlop J, Stevens HP et al: Connexin 26 mutations in hereditary non-syndromic sensorineural deafness. Nature 1997; 387: $80-83$.

9 Xia JH, Liu CY, Tang BS et al: Mutations in the gene encoding gap junction protein beta- 3 associated with autosomal dominant hearing impairment. Nat Genet 1998; 20: 370-373.

10 Verhoeven K, Van Laer L, Kirschhofer $\mathrm{K}$ et al: Mutations in the human alpha-tectorin gene cause autosomal dominant nonsyndromic hearing impairment. Nat Genet 1998; 19: 60-62.

11 Bruzzone R, White TW, Paul DL: Connections with connexins: The molecular basis of direct intercellular signaling. Eur J Biochem 1996; 238: 1-27.

12 Kumar NM, Gilula NB: The gap junction communication channel. Cell 1996; 9: $381-388$.

13 Kikuchi T, Adams JC, Miyabe Y, So E, Kobayashi T: Potassium ion recycling pathway via gap junction systems in the mammalian cochlea and its interruption in hereditary nonsyndromic deafness. Med Electron Microsc 2000; 33: 51-56.

14 Löffler J, Nekahm D, Hirst-Stadlmann A et al: Sensorineural hearing loss and the incidence of Cx26 mutations in Austria. Eur $J$ Hum Genet 2001; 9: 226-230.
15 Zelante L, Gasparini P, Estivill X et al: Connexin 26 mutations associated with the most common form of non-syndromic neurosensory autosomal recessive deafness (DFNB1) in Mediterraneans. Hum Mol Genet 1997; 6: 1605-1609.

16 Abe S, Usami S, Shinkawa H, Kelley PM, Kimberling WJ: Prevalent connexin 26 gene (GJB2) mutations in Japanese. J Med Genet 2000; 37: $41-43$.

17 Estivill X, Fortina P, Surrey S et al: Connexin-26 mutations in sporadic an inherited sensorineural deafness. Lancet 1998; 351: 394-398.

18 Denoyelle F, Weil D, Maw MA et al: Prelingual deafness: high prevalence of a 30delG mutation in the connexin 26 gene. Hum Mol Genet 1997; 6: 2173-2177.

19 Antoniadi T, Gronskov K, Sand A, Pampanos A, Brondum-Nielsen K, Petersen MB: Mutation analysis of the GJB2 (connexin26) gene by DGGE in Greek patients with sensorineural deafness. Hum Mut 2000; 16: 7-12.

20 Morlé L, Bozon M, Alloisio N: A novel C202F mutation in the connexin26 gene (GJB2) associated with autosomal dominant isolated hearing loss. J Med Genet 2000; 37: 368-370.

21 Denoyelle F, Lina-Granade G, Plauchu H et al: Connexin 26 gene linked to a dominant deafness. Nature 1998; 393: 319-320.

22 Gasparini P, Rabionet R, Barbujani G et al: High carrier frequency of the 35delG deafness mutation in European populations. Eur Hum Genet 2000; 8: 19-23.

23 Worldwide survey of the delta F508 mutation: Report from the cystic fibrosis genetic analysis consortium. Am J Hum Genet 1990; 47: 354-359.

24 Tyagi S, Kramer FR: Molecular beacons: probes that fluoresce upon hybridization. Nat Biotechnol 1996; 14: 303-308.

25 SantaLucia Jr J: A unified view of polymer, dumbbell, and oligonucleotide DNA nearest- neighbour thermodynamics. Proc Natl Acad Sci USA 1998; 95: 1460-1465.

26 Szuhai K, Ouweland JM, Dirks RW et al: Simultaneous A8344G heteroplasmy and mitochondrial DNA copy number quantification in Myoclonus Epilepsy and Ragged-Red Fibers (MERRF) syndrome by a multiplex Molecular Beacon based real-time fluorescence PCR. Nucleic Acids Res 2001; 29: E13.

27 Szuhai K, Sandhaus E, Kolkman-Uljee SM et al: A novel strategy for human papillomavirus detection and genotyping with SybrGreen and molecular beacon polymerase chain reaction. Am J Pathol 2001; 159: 1651-1660.

28 Murgia A, Orzan E, Polli R et al: Cx26 deafness: mutation analysis and clinical variability. J Med Genet 1999; 36: 829-832.

29 Denoyelle F, Marlin S, Weil D et al: Clinical features of the prevalent form of childhood deafness, DFNB1, due to a connexin-26 gene defect: implication for genetic counselling. Lancet 1999; 353: $1298-1303$.

30 Marlin S, Garabedian E-N, Roger G et al: Connexin 26 gene mutations in congenitally deaf children. Arch Otolaryngol Head Neck Surg 2001; 127: $927-933$

31 Wiuf C: Do delta F508 heterocygotes have a selective advantage?. Genet Res 2001; 78: 41-47.

32 Rabionet R, Estivil X: Allele specific oligonucleotide analysis of the common deafness mutaion 35delG in the connexin 26 (GJB2) gene. J Med Genet 1999; 36: 260-261.

33 Casademont I, Chevrier D, Denoyelle F, Petit C, Guesdon J-L: A simple and reliable method for the detection of the 30delG mutation of the Cx26 gene. Mol Cell Probes 2000; 14: 149-152.

34 Lamartine J, Munhoz Essenfelder G, Kibar Z et al: Mutations in GJB6 cause hidrotic ectodermal dysplasia. Nat Genet 2000; 26: $142-144$ 